\title{
Changes in Medicaid Utilization and Spending Associated with Homeless Adults' Entry into Permanent Supportive Housing
}

\author{
Mara A. G. Hollander, $P h D^{1,2}$ (1) Evan S. Cole, $P h D^{3}$, Julie M. Donohue, $P h D^{3}$, and \\ Eric T. Roberts, $P h D^{3}$
}

'Department of Health Policy and Management, Johns Hopkins Bloomberg School of Public Health, Baltimore, MD, USA; ${ }^{2}$ Center for Mental Health and Addiction Policy Research, Johns Hopkins Bloomberg School of Public Health, Baltimore, MD, USA; ${ }^{3}$ Department of Health Policy and Management, University of Pittsburgh Graduate School of Public Health, Pittsburgh, PA, USA.

\begin{abstract}
BACKGROUND: There is growing interest in financing housing and supportive services for homeless individuals through Medicaid. Permanent Supportive Housing (PSH), which integrates non-time-limited housing with supportive services for people who are disabled and chronically homeless, has seen rapid growth in the last decade, but clear evidence on the long-term impacts of PSH, needed to guide state efforts to finance some PSH services through Medicaid, is lacking.

OBJECTIVE: Assess changes in Medicaid expenditures and utilization associated with receiving $\mathrm{PSH}$.

DESIGN: Cohort study using a difference-in-differences approach.

PARTICIPANTS: A total of 1226 PA Medicaid enrollees who entered PSH 2011-2016 and remained in PSH for 180 days or more, and a matched comparison cohort of 970 enrollees experiencing housing instability who did not receive PSH.
\end{abstract}

MAIN MEASURES: Medicaid spending in aggregate, and on behavioral and physical health services; emergency department (ED) visits and inpatient hospital stays.

KEY RESULTS: Three years after PSH entry, spending decreased by an average of $\$ 145 /$ month in the PSH cohort relative to changes in the comparison cohort ( $p=$ 0.046), with the greatest relative spending reductions occurring for residential behavioral health $(\$ 64, p<0.001)$ and inpatient non-behavioral health services $\mathbf{( \$ 8 9 , p =}$ $0.001)$. We also found relative reductions in ED use (4.7 visits / 100 person-months, $p=0.010$ ) and inpatient hospital stays ( 1.6 visits $/ 100$ person-months, $p<0.001$ ).

CONCLUSIONS: These results can inform emerging state efforts to finance PSH services through Medicaid. Additional state expenditures to expand financing for PSH services could be partially offset by reductions in Medicaid spending, in part by facilitating a shift in treatment to outpatient from acute care settings.

KEY WORDS: Permanent Supportive Housing; homelessness; Medicaid; health care utilization; health care expenditures.

$\overline{\text { An earlier version of this paper was presented at the } 2019 \text { AcademyHealth }}$ Annual Research Meeting in Washington, DC.

Received July 17, 2020

Accepted December 13, 2020

Published online January 29, 2021
$\mathrm{J}$ Gen Intern Med 36(8):2353-60

DOI: $10.1007 / \mathrm{s} 11606-020-06465-\mathrm{y}$

(C) Society of General Internal Medicine 2021

$\mathrm{T}$ here is growing interest in financing housing and supportive services for homeless individuals through Medicaid. ${ }^{1}$ Homeless populations' high burden of serious mental illness, substance use disorders (SUD), and chronic physical health conditions contribute to elevated rates of hospital and emergency department (ED) use, the costs of which disproportionately accrue to Medicaid. ${ }^{2}$ This has prompted emerging efforts in Medicaid programs to address health needs linked to homelessness, including payment for support services to help individuals receive and maintain stable housing, with the goal of improving health and reducing long-term medical spending in populations with a history of homelessness.

Programs to provide stable housing, such as Permanent Supportive Housing (PSH), have attracted particular interest from policymakers and experienced rapid growth in the last decade. ${ }^{3}$ PSH integrates non-time-limited housing with supportive services, including relocation assistance and tenancysustaining services, for people who are disabled and chronically homeless (Appendix). ${ }^{4}$

Medicaid programs can pay for supportive services in PSH that fall outside the scope of traditional health benefits, but cannot pay for room and board costs. Several states are considering options to finance a greater share of PSH costs through their Medicaid programs, which typically require a waiver of program rules and demonstration of budget neutrality or cost-effectiveness over the term of the waiver (2-5 years). ${ }^{4,5}$

However, there is limited evidence on the long-term impacts of PSH on health care utilization and expenditures. Several studies have linked receiving PSH to reductions in inpatient and ED use and increases in behavioral health care utilization in populations with serious mental health diagnoses, but other analyses found few changes in spending attributable to $\mathrm{PSH}^{4}{ }^{4-16}$ A recent report by the National 
Academies of Science, Engineering, and Medicine cited a lack of clear evidence on the long-term impacts of PSH, noting that existing studies were limited by small samples, geographic homogeneity, and follow-up periods of less than 2 years - shorter than most individuals' duration of PSH enrollment and the period over which the benefits of stable housing might accrue both to residents and Medicaid. ${ }^{4}, 10-12,17-22$

We address limitations of prior research by studying a cohort of 1226 geographically diverse PSH recipients enrolled in Pennsylvania Medicaid during 2011-2017, among whom we assessed changes in Medicaid expenditures and utilization from up to 15 months before to 3 years following PSH entry. We compared these changes to trends in a matched cohort of individuals experiencing housing instability who did not receive PSH using a difference-in-differences analysis.

\section{METHODS}

This study was reviewed by the University of Pittsburgh Institutional Review Board and deemed exempt because it is a secondary analysis of deidentified data.

\section{Data}

We analyzed Medicaid enrollment and claims data from the Pennsylvania Medicaid program linked to Homeless Management Information Systems (HMIS) records from 54 of Pennsylvania's 67 counties for the period 2011-2017. HMIS captures Department of Housing and Urban Developmentfinanced housing services provided to individuals and families who are homeless or at risk of homelessness. ${ }^{23}$ These data include housing service dates (e.g., PSH entry and exit) and provision of short-term housing services (e.g., overnight shelters) separate from PSH.

HMIS and Medicaid data were matched by the Pennsylvania Department of Human Services using individual-level identifiers. ${ }^{24}$ Our linked Medicaid-HMIS data encompassed Pittsburgh, the majority of Pennsylvania's rural counties, and several midsized urban areas. We were unable to obtain housing data for Philadelphia and 12 other counties that use separate HMIS systems (Appendix).

\section{Treatment Sample}

We identified Pennsylvania Medicaid enrollees who entered PSH between April 1, 2012, and December 31, 2016, were age 21 or older at the time of entry, and stayed in PSH for at least 180 days, consistent with this program's goal of providing long-term housing.

To analyze changes in Medicaid utilization and spending before and after PSH entry, we required individuals to meet minimum Medicaid enrollment criteria in three periods: (1) at least 4 months between 16 and 28 months before PSH entry (to assess established health conditions); (2) 6 months during a baseline period (7-15 months before PSH entry); and (3) 6 months in the year immediately following PSH entry. This allowed us to assess the pre-PSH characteristics of Medicaid enrollees and examine changes in Medicaid spending and utilization before and after PSH entry while recognizing that it is common for individuals to have gaps in Medicaid coverage. $^{25}$

\section{Comparison Sample}

We identified a comparison sample of Medicaid enrollees with similar demographic and health characteristics as PSH recipients who did not receive PSH but received other housing services indicative of episodic or chronic homelessness (e.g., emergency shelter stays). This comparison sample controls for secular trends in spending and utilization associated with homelessness but unrelated to PSH. We identified this comparison sample in two stages.

First, among Pennsylvania Medicaid enrollees who received housing services other than PSH, we used propensity score matching to identify an initial comparison group of individuals who resembled PSH recipients on time-invariant characteristics, including gender, race and ethnicity, and chronic conditions (e.g., SUD, diabetes) reported on Medicaid claims between 2011 and 2017. We constructed a propensity score that summarized individuals' propensity to receive PSH as a function of these characteristics and matched each PSH recipient to up to four comparison individuals within the same propensity score quantile (of 40 quantiles) (Appendix).

Second, we identified a reference month for each individual in the comparison sample identified in the first stage. We selected this reference month so that spending trends in the 7-15 months preceding it most closely resembled those of PSH recipients in the 7-15 months prior to PSH entry. We focused on this period because it generally preceded marked increases in Medicaid spending 6 months before receiving PSH that was common among adults in our intervention group. These spending increases were concentrated in behavioral health treatment and may reflect use of care that precedes entry into PSH (e.g., residential treatment for a substance use disorder) or health system engagement to obtain medical documentation of a disability (a prerequisite for PSH eligibility). We excluded trends likely related to but preceding PSH entry by excluding the 6 months prior to PSH entry in our treatment sample and the 6 months preceding the reference month in our comparison sample. ${ }^{26}$ We discuss implications of this strategy below and in the Appendix.

\section{Outcome Measures}

We used Medicaid claims and encounter data to assess spending and utilization. We measured Medicaid spending using paid amounts in managed care and fee-for-service claims. We analyzed spending in total, in three major service categories 
(behavioral health, physical health, and pharmacy spending), and in subcategories, following prior literature. ${ }^{7,}{ }^{12,}{ }^{27-30} \mathrm{We}$ also analyzed 18 measures of utilization, including ED visits, behavioral health and acute care inpatient stays, and primary care visits (Appendix).

\section{Statistical Analysis}

We conducted difference-in-difference analyses to compare changes in spending and utilization from baseline (7-15 months prior to PSH entry or the reference month) to up to 3 years following PSH entry among PSH recipients to changes in the comparison group following the reference month (i.e., differential changes). The unit of analysis was the personmonth.

For spending outcomes, we estimated differential changes between the PSH and comparison cohorts using a two-part regression model: a probit model to account for personmonths with no spending, and a generalized linear model with a log link and gamma variance function for months in which individuals incurred $>\$ 0$ in spending. ${ }^{31}$ For utilization measures, we used linear models (Appendix). We adjusted for age, gender, race/ethnicity, urbanicity, county, and time-varying health conditions. Standard errors were clustered at the person level to account for correlation between months within individuals. We report adjusted differential changes in monthly spending or utilization per member between the PSH and matched comparison samples from baseline through the first, second, and third year following PSH entry. We also measured the change in the composition of spending from the baseline period to year 3 .

\section{Sensitivity and Supplementary Analyses}

We conducted a sensitivity analysis that omitted the period 19 months prior to PSH entry (or the reference month for the comparison group) to further limit the impact of preenrollment increases in spending that might cause us to conflate long-run changes with regression to the mean effects.

We conducted two supplementary analyses. First, we compared the characteristics of individuals who remained enrolled in Medicaid 3 years after PSH entry or the reference month. To the extent Medicaid attrition is lower among PSH recipients with chronic health conditions that predispose individuals to need more care than among individuals in the comparison group, our estimates may be biased away from finding changes in spending and utilization associated with PSH. Second, we examined spending trends prior to the baseline period in both cohorts to evaluate whether long-run spending trends were similar prior to the baseline period. This establishes that spending trends, excluding increases 1-6 months preceding PSH entry, would likely have remained similar between the cohorts had individuals in our treatment sample not received PSH.

\section{RESULTS}

\section{Cohort Demographics and Health}

Among PSH recipients in our cohort $(n=1226), 58.1 \%$ were female, and $30.2 \%$ were non-Hispanic Black. Behavioral health burden was high: $95.0 \%$ of recipients were diagnosed with a mental illness and $66.2 \%$ with an SUD. More than onequarter $(25.4 \%)$ had been diagnosed with the hepatitis $\mathrm{C}$ virus (HCV). A very small proportion of our sample (an $n$-size too small to report) were newly enrolled through the Medicaid expansion, which began in Pennsylvania in 2015. As expected, the matched comparison population $(n=970)$ closely resembled PSH recipients (Table 1).

\section{Unadjusted Estimates}

At baseline ( 7 to 15 months prior to PSH entry), average monthly Medicaid spending among individuals in the PSH group was $\$ 1337$ and declined to $\$ 1262$ in the third year following PSH entry. In the comparison group, average spending increased from $\$ 896$ at baseline to $\$ 1038$ in year 3 (Fig. 1). The unadjusted differential decline in monthly spending was $\$ 218$. From baseline to year 3, we found differential declines in behavioral health (\$166/monthly per person) and physical health spending ( $\$ 100 /$ monthly per person), but relative increases in pharmacy spending ( $\$ 61 /$ monthly per person) in the PSH versus comparison cohorts.

We observed spending increases in the PSH group, concentrated primarily in the 6 months preceding PSH entry. We excluded these months from our estimates of adjusted spending changes before and after PSH entry.

\section{Adjusted Estimates}

Adjusted monthly spending among PSH recipients declined from approximately $\$ 1228$ in the baseline period to $\$ 1156$ in year 3, but increased among individuals in the comparison cohort from $\$ 957$ in baseline to $\$ 1030$ in year 3. The relative decline in total spending from baseline to year 3 in the PSH versus comparison cohorts was $-\$ 145$ (95\% CI $[-\$ 289,-\$ 3]$; $p=0.046 ; 12 \%$ reduction) (Table 2 ; Appendix). Relative declines in spending were seen for behavioral health $(-\$ 119 ; 95 \%$ CI $[-\$ 191,-\$ 48] ; p=0.001)$ and physical health services ($\$ 73 ; 95 \%$ CI $[-\$ 133,-\$ 13] ; p=0.017)$, attributable primarily to decreases in residential behavioral health $(-\$ 64 ; 95 \%$ CI [$\$ 95,-\$ 34] ; p<0.001)$ and inpatient non-behavioral health care spending (-\$89; 95\% CI $[-\$ 139,-\$ 39] ; p=0.001)$. Almost all spending measures show similar changes in spending in a sensitivity analysis in which the 9 months, rather than 6 months, prior to PSH placement were excluded.

Among PSH recipients, the composition of spending also changed from the baseline period to year 3 (Fig. 2). Outpatient pharmacy spending increased from 17.4 to $26.8 \%$ of total spending, and case management increased from 5.3 to $8.9 \%$. Residential behavioral health (11.5 to $3.8 \%$ ), inpatient behavioral health (6.5 to 3.6\%), and inpatient non-behavioral health 
Table 1 Demographic Characteristics

\begin{tabular}{|c|c|c|c|}
\hline & \multirow{2}{*}{$\begin{array}{l}\begin{array}{l}\text { PSH } \\
\text { cohort }(n \\
=1226)\end{array} \\
n(\%)\end{array}$} & \multirow{2}{*}{$\begin{array}{l}\text { Comparison }(n \\
=970) \\
n(\%)\end{array}$} & \multirow[t]{2}{*}{$\begin{array}{l}p \\
\text { value* }\end{array}$} \\
\hline & & & \\
\hline emale, \% & $712(58.1)$ & $563(58)$ & 0.987 \\
\hline $\begin{array}{l}\text { Age, \% in category } \\
22-34 \\
35-44 \\
45-54 \\
55+ \\
\text { Race, \% in category }\end{array}$ & $\begin{array}{l}469(38.3) \\
291(23.7) \\
321(26.2) \\
145(11.8)\end{array}$ & $\begin{array}{l}435(44.8) \\
239(24.6) \\
214(22.1) \\
82(8.5)\end{array}$ & $0.001^{*}$ \\
\hline $\begin{array}{l}\text { Non-Hispanic White } \\
\text { Non-Hispanic Black } \\
\text { Hispanic } \\
\text { Other }\end{array}$ & $\begin{array}{l}802(65.4) \\
370(30.2) \\
35(2.9) \\
19(1.5)\end{array}$ & $\begin{array}{l}606(62.5) \\
326(33.6) \\
-_{-}^{\dagger} \\
-\dagger\end{array}$ & 0.161 \\
\hline \multicolumn{4}{|c|}{ Medicaid managed care contracting region, $\%$ in category } \\
\hline $\begin{array}{l}\text { Lehigh } \\
\text { New East } \\
\text { New West } \\
\text { Southeast } \\
\text { Southwest }\end{array}$ & $\begin{array}{l}106(8.6) \\
64(5.2) \\
132(10.8) \\
16(1.3) \\
908(74.1)\end{array}$ & $\begin{array}{l}97(10) \\
52(5.4) \\
102(10.5) \\
13(1.3) \\
706(72.8)\end{array}$ & 0.869 \\
\hline $\begin{array}{l}\text { Resident of Allegheny } \\
\text { County, } \%\end{array}$ & $686(56)$ & $521(53.7)$ & 0.294 \\
\hline $\begin{array}{l}\text { Resident of rural county } \\
\%^{\ddagger}\end{array}$ & $370(30.2)$ & 307 (31.6) & 0.459 \\
\hline $\begin{array}{l}\text { Dual enrollee in Medicare } \\
\text { and Medicaid, } \% \S\end{array}$ & $83(6.8)$ & $65(6.7)$ & 0.949 \\
\hline $\begin{array}{l}\text { Eligible for Medicaid } \\
\text { through a disability } \\
\text { pathway, \% } \\
\text { Diagnoses, \% }\end{array}$ & $559(45.6)$ & $427(44)$ & 0.461 \\
\hline $\mathrm{C}$ virus & $312(25.4)$ & $232(23.9)$ & 0.409 \\
\hline $\begin{array}{l}\text { Human immunodeficiency } \\
\text { virus }\end{array}$ & $31(2.5)$ & $22(2.3)$ & 0.693 \\
\hline Tobacco use disorder & $\begin{array}{l}1028 \\
(83.8)\end{array}$ & $805(83)$ & 0.590 \\
\hline Substance & $811(66.2)$ & $629(64$. & 0.523 \\
\hline Menta & $1165(95)$ & 923 & 0.889 \\
\hline $\begin{array}{l}\text { Cardiovascular disease, } \\
\text { extra low }\end{array}$ & $663(54.1)$ & $539(55.6)$ & 0.486 \\
\hline Gastrointestinal, low ${ }^{\mathrm{II}}$ & $711(58)$ & $541(55.8)$ & 0.297 \\
\hline Infectious, low & $395(32.2)$ & $296(30.5)$ & 0.393 \\
\hline 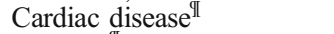 & $693(56.5)$ & $538(55.5)$ & 0.619 \\
\hline Diabetes & $200(16.3)$ & $152(15.7)$ & 0.683 \\
\hline
\end{tabular}

*p value for differences in proportions between the PSH and comparison cohorts. Differences were assessed using chi-square tests for categorical variables

†Cell values haves been suppressed due to small cell sizes

$\$$ Rurality was assessed at the county level according to a definition provided by The Center for Rural Pennsylvania

${ }^{\xi}$ If an enrollee had $\geq 1$ month in the years 2011-2017 in which they were dually enrolled in Medicare and Medicaid, they were considered to have been a dual enrollee Medicare and Medicaid

"If an enrollee had $\geq 1$ month in the years 2011-2017 in which they were enrolled in Medicaid through a disability pathway, they were considered to have been enrolled through a disability pathway

${ }^{\top}$ Categories were assessed using the Chronic Illness \& Disability Payment System and Medicaid Rx (CDPS-MRX). "Low" and "extra low" refer to levels of severity. Categories listed here are the top 5 CDPS-MRX categories present in the PSH cohort

(19.4 to $15.3 \%$ ) spending all declined as a proportion of total spending from the baseline period to year 3 .

The number of ED visits was nearly equal between the PSH cohort and comparison cohort during the baseline period. However, ED use declined among PSH recipients relative to the comparison group 3 years after PSH entry $(-4.7$ visits per 100 person-months by year 3 (95\% CI $[-8.3,-1.0], p=$ $0.010,20 \%$ from baseline) (Table 3; Appendix). There was also a relative decline in acute care hospitalizations (1.6 fewer visits per 100 person-months by year three; $95 \% \mathrm{CI}[-2.5,-$ $0.7] ; p<0.001 ; 42 \%$ decrease) and days spent in residential SUD treatment $(27.3$ fewer days by year three; 95\% CI [- 42.4, - 12.2]; $p<0.001 ; 71 \%$ decrease). Community mental health visits increased among the PSH cohort relative to the comparison cohort in years 1 and 2 (increase of 87.0 visits per 100 person-months in year 1; 95\% CI [66.1, 107.8]; $p<0.001)$.

\section{Supplementary Analyses}

A supplementary analysis examined the demographics of those who remained enrolled in Medicaid 3 years after PSH entry or the reference month of the comparison group (Appendix). We found no difference in the characteristics of individuals in the PSH versus comparison cohorts who remained enrolled in Medicaid at 36 months, as measured by established chronic conditions or other demographic characteristics. Thus, it is unlikely that our estimates would have been biased by differential attrition from Medicaid by health or demographic characteristics.

We also compared spending trends prior to baseline (16 to 27 months prior to PSH entry or the reference month for the comparison group) in the PSH and comparison cohorts. Two models revealed no between-group difference in spending trends over this period, suggesting that long-run trends would have remained similar had our treatment sample not received PSH. Thus, spending changes in the comparison group approximate long-run changes that would have been expected to occur in the treatment group without PSH (Appendix).

\section{DISCUSSION}

We analyzed a cohort of adults enrolled in Pennsylvania Medicaid who received PSH and a matched comparison group of unstably housed individuals who did not receive PSH to estimate long-term changes in Medicaid spending and utilization associated with receiving PSH. We estimated that, 3 years after entering PSH, monthly Medicaid spending was $\$ 145$ per person lower than would have been expected had adults not received PSH, a $12 \%$ reduction from baseline spending. Annually, these spending reductions represent an average savings of $\$ 1740$ per PSH recipient. We estimated that PSH was associated with decreases in ED use, acute care hospitalizations, and days spent in residential SUD care, and an increase in community mental health use in the first 2 years after PSH entry. These estimates are consistent with our finding that the distribution of spending among PSH enrollees shifted from acute and emergency care use at baseline towards greater outpatient and pharmacy care use 3 years after PSH entry. For example, after 3 years, the share of spending on outpatient pharmacy care increased from 17 to nearly $27 \%$, the share of spending on inpatient and residential behavioral health 
a Total Spending

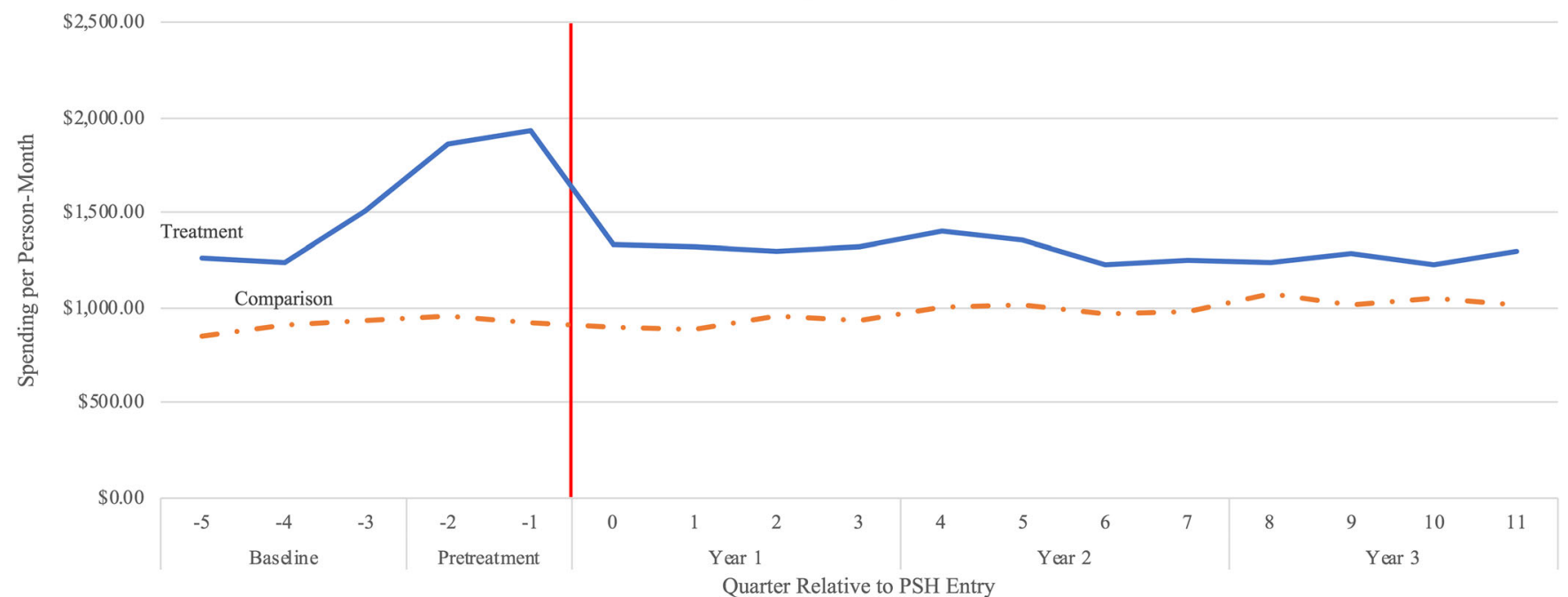

b Spending by Category

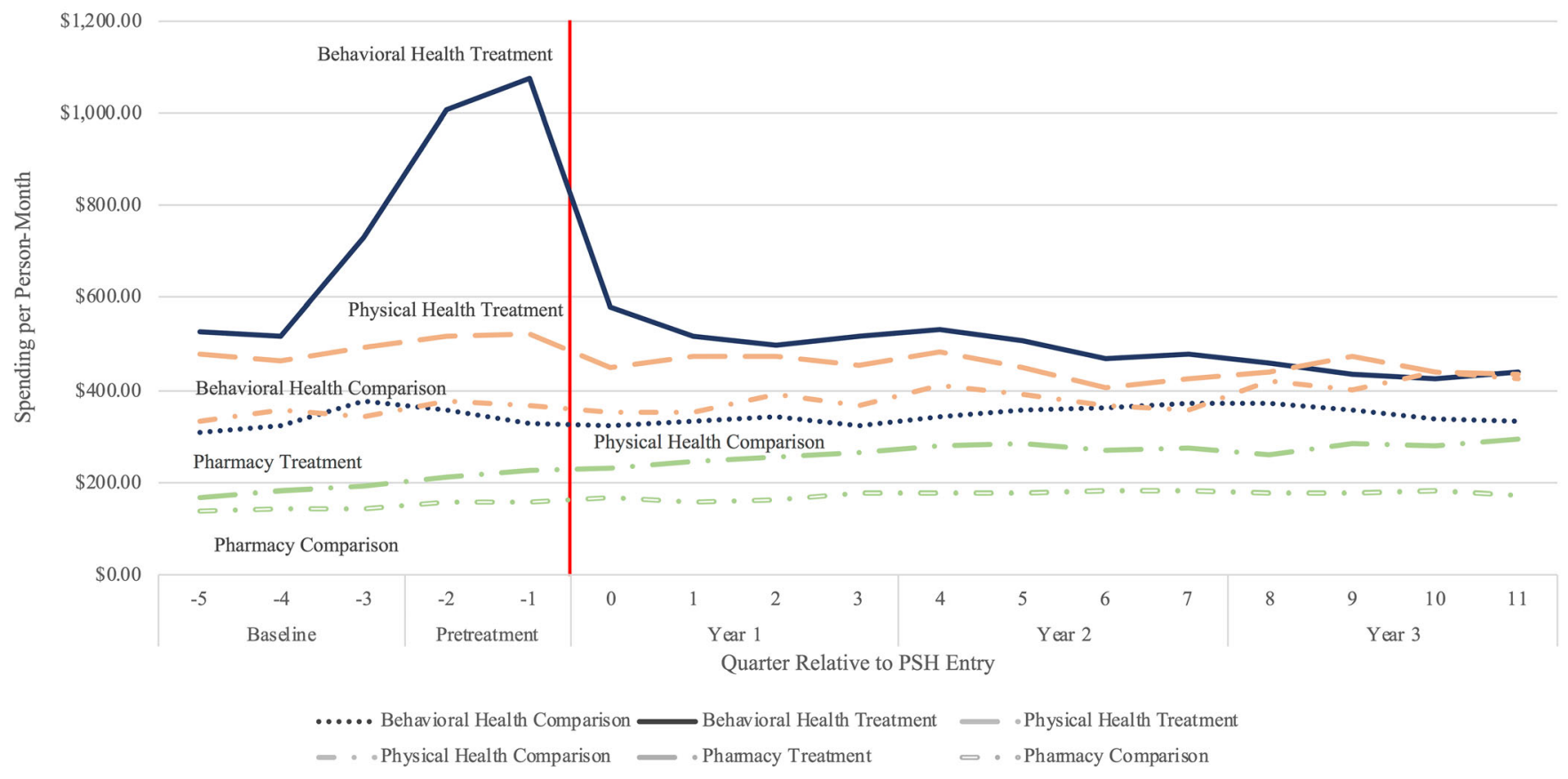

Fig. 1 Unadjusted spending. Unadjusted spending from 15 months prior to the start of PSH (or the reference date, for the comparison group) until 35 months after the start of PSH. Unadjusted spending is calculated as a total of paid amounts on all claims included in the category. Total spending includes all claims during the study period.

treatment declined from 18 to $7 \%$, and the share of spending on non-behavioral health inpatient care fell from 19 to $15 \%$.

Adults in our study who received PSH exhibited a high burden of mental illnesses and SUD: nearly all had a diagnosed mental health disorder, and two-thirds had a diagnosed SUD. The prevalence of these conditions was higher than has been reported in federal estimates, which found that two-thirds of PSH recipients nationally had a mental health diagnosis and approximately $40 \%$ had a SUD. ${ }^{32}$ Consistent with the prevalence of these conditions in our sample, we found that adults used inpatient and residential behavioral health services intensively prior to receiving PSH. Use declined after PSH entry, potentially as better housing enabled individuals to manage their chronic health conditions in outpatient settings. ${ }^{4}$ One study found improvements in self-rated health and reductions in limitations to physical and social activity after adults were placed into $\mathrm{PSH}^{33}$

We observed marked increases in health care spending and use before adults entered PSH. These increases may reflect patterns of care that facilitate entry into PSH and are consistent with prior research that ED and inpatient use increases immediately before and after homeless adults enter shelters. ${ }^{34}$ To the extent homeless individuals become connected to housing providers as a result of using care - whose costs may be borne 
Table 2 Relative Changes in Spending from Baseline: PSH Enrollees Versus Matched Controls

\begin{tabular}{|c|c|c|c|c|c|c|}
\hline & \multirow{2}{*}{\multicolumn{2}{|c|}{$\begin{array}{l}\text { Baseline, per person-month } \\
7 \text { to } 15 \text { months before PSH } \\
\text { entry) }\end{array}$}} & \multicolumn{4}{|c|}{ Year 3 differential change from baseline, PSH vs. comparison } \\
\hline & & & \multicolumn{4}{|c|}{ (Months 24 to 35 after PSH entry) } \\
\hline & PSH cohort & $\begin{array}{l}\text { Comp. } \\
\text { cohort }\end{array}$ & $\begin{array}{l}\text { PSH } \\
\text { cohort* }\end{array}$ & $\begin{array}{l}\text { Comp. } \\
\text { cohort }^{\dagger}\end{array}$ & $\begin{array}{l}\text { Difference (bootstrapped } 95 \% \\
\text { CI) }\end{array}$ & $p$ value $^{*}$ \\
\hline Total & $\$ 1228.19$ & $\$ 956.71$ & $-\$ 72.53$ & $\$ 72.92$ & $-\$ 145.45(-\$ 288.80,-\$ 3.37)$ & 0.046 \\
\hline Behavioral health ${ }^{\S}$ & $\$ 511.85$ & $\$ 336.69$ & $-\$ 118.34$ & $\$ 0.59$ & $-\$ 118.93(-\$ 190.50,-\$ 47.79)$ & 0.001 \\
\hline Physical health" & $\$ 415.36$ & $\$ 347.02$ & $-\$ 23.58$ & $\$ 49.11$ & $-\$ 72.69(-\$ 132.80,-\$ 13.23)$ & 0.017 \\
\hline Pharmacy & $\$ 169.44$ & $\$ 143.07$ & $\$ 66.12$ & $\$ 33.79$ & $\$ 32.34(\$ 1.03, \$ 64.71)$ & 0.047 \\
\hline ED & $\$ 51.14$ & $\$ 45.76$ & $-\$ 12.56$ & $-\$ 4.26$ & $-\$ 8.30(-\$ 16.04,-\$ 0.83)$ & 0.032 \\
\hline Case management & $\$ 51.50$ & $\$ 27.69$ & $\$ 26.44$ & $\$ 6.04$ & $\$ 20.40(\$ 7.07, \$ 33.93)$ & 0.003 \\
\hline Community behavioral health & $\$ 199.14$ & $\$ 116.03$ & $-\$ 16.23$ & $\$ 23.35$ & $-\$ 39.58(-\$ 71.51,-\$ 8.00)$ & 0.015 \\
\hline Residential behavioral health & $\$ 111.80$ & $\$ 72.49$ & $-\$ 78.43$ & $-\$ 13.83$ & $-\$ 64.61(-\$ 95.33,-\$ 33.63)$ & 0.000 \\
\hline $\begin{array}{l}\text { Inpatient non-behavioral } \\
\text { health }\end{array}$ & $\$ 188.66$ & $\$ 117.79$ & $-\$ 53.99$ & $\$ 35.21$ & $-\$ 89.20(-\$ 139.40,-\$ 38.57)$ & 0.001 \\
\hline
\end{tabular}

*Difference between baseline spending among PSH cohort and year 3 spending among PSH cohort

tDifference between baseline spending among comparison cohort and year 3 spending among comparison cohort

${ }^{*} p$ value for differences in differential changes between the PSH and comparison cohorts

${ }^{\xi}$ Includes community behavioral health, case management, residential behavioral health, and inpatient behavioral health spending

"Includes ED, non-behavioral health inpatient, primary care, other physician services, other ambulatory care services, and other spending

by Medicaid - there may be an opportunity for Medicaid programs to proactively identify homeless individuals who are eligible for PSH before they incur costly care. Expansions of Medicaid under the Affordable Care Act have increased insurance coverage among homeless individuals, increasing the incentive for Medicaid programs to identify homeless individuals who may be candidates for PSH prior to incidents that require expensive and complex care. ${ }^{35}$

This study had limitations. First, we observed increases in Medicaid spending and utilization among PSH recipients prior

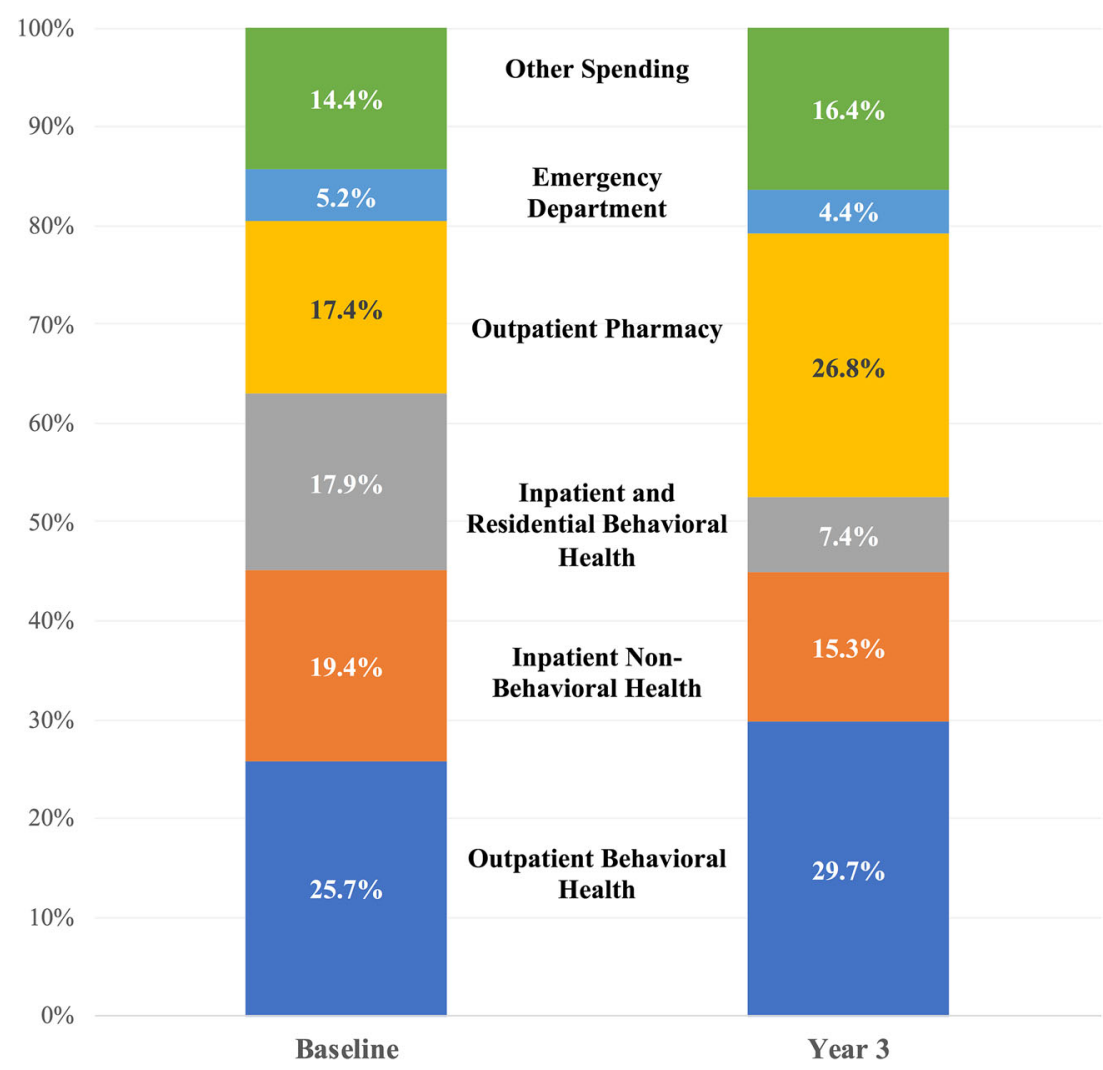

Fig. 2 Spending as a proportion of total spending by the Permanent Supportive Housing cohort, baseline period and year 3. Adjusted spending as a proportion of total spending in the baseline period (7-15 months prior to entering PSH) and in the third year after entering PSH. Outpatient pharmacy spending and case management become a larger proportion of overall spending by year 3 . Residential behavioral health care, inpatient behavioral health, and inpatient non-behavioral health become a smaller proportion of overall spending by year 3 . Because we top-coded each spending variable to the 99th percentile to limit the influence of high-cost outliers, percentages may not align with calculated percentages in other figures. 
Table 3 Relative Changes in Utilization from Baseline: PSH Enrollees Versus Matched Controls

\begin{tabular}{|c|c|c|c|c|c|c|}
\hline & \multirow{2}{*}{\multicolumn{2}{|c|}{$\begin{array}{l}\text { Baseline, per person- } \\
\text { month } \\
\text { (7 to } 15 \text { months before } \\
\text { PSH entry) }\end{array}$}} & \multicolumn{4}{|c|}{ Year 3 differential change from baseline, PSH vs. comparison } \\
\hline & & & \multicolumn{4}{|c|}{ (Months 24 to 35 after PSH entry) } \\
\hline & $\begin{array}{l}\text { PSH } \\
\text { cohort }\end{array}$ & $\begin{array}{l}\text { Comp. } \\
\text { cohort }\end{array}$ & $\begin{array}{l}\text { PSH } \\
\text { cohort* }\end{array}$ & $\begin{array}{l}\text { Comp. } \\
\text { cohort }^{\dagger}\end{array}$ & Difference (95\% CI) & value $^{*}$ \\
\hline ED visits & 23.59 & 21.56 & -7.23 & -2.57 & $-4.66(-8.29,-1.04)$ & 0.010 \\
\hline Acute care hospitalization visits & 3.77 & 2.50 & -1.45 & 0.15 & $-1.60(-2.47,-0.73)$ & 0.000 \\
\hline Primary care visits & 27.10 & 24.60 & -0.07 & -3.96 & $3.89(-0.48,8.25)$ & 0.080 \\
\hline Community mental health treatment days & 184.13 & 107.20 & 28.88 & 12.10 & $16.79(-11.76,45.33)$ & 0.250 \\
\hline $\begin{array}{l}\text { Community substance use disorder } \\
\text { treatment days }\end{array}$ & 93.23 & 61.82 & -9.20 & 11.38 & $-20.58(-56.74,15.59)$ & 0.260 \\
\hline Residential mental health treatment days & 0.20 & 3.31 & -0.33 & -2.93 & $2.61(-1.18,6.40)$ & 0.180 \\
\hline Residential substance use disorder days & 38.47 & 20.80 & -23.75 & 3.57 & $\begin{array}{l}-27.32(-42.44,- \\
12.20)\end{array}$ & 0.000 \\
\hline Inpatient mental health treatment days & 2.79 & 2.22 & -1.41 & -0.61 & $-0.80(-1.65,0.05)$ & 0.070 \\
\hline $\begin{array}{l}\text { Inpatient substance use disorder treatment } \\
\text { days }\end{array}$ & 0.10 & 0.09 & -0.07 & -0.04 & $-0.03(-0.15,0.09)$ & 0.640 \\
\hline
\end{tabular}

*Difference between baseline utilization among PSH cohort and year 3 utilization among PSH cohort

tDifference between baseline utilization among comparison cohort and year 3 utilization among comparison cohort

${ }_{t} p$ value for differences in differential changes between the PSH and comparison cohorts

to PSH entry but did not see similar trends in our comparison population. These patterns likely reflect the unique circumstances under which individuals establish eligibility for PSH and underscore the difficulty of isolating effects of PSH from trends preceding PSH entry. To mitigate bias that could arise from these pre-PSH trends, we excluded the 6 months before PSH entry, when these spending increases were most pronounced. However, our estimates remain susceptible to bias if the comparison sample does not correctly control for secular trends in spending and utilization (excluding the 6 months prior to PSH entry) unrelated to the receipt of PSH. Spending trends were comparable in the treatment and comparison groups 16 to 27 months prior to PSH entry (or reference month), suggesting that our comparison group provides a plausible control for these secular trends. However, we cannot rule out the possibility that subsequent trends between these groups could have differed for reasons unrelated to PSH. Second, we identified our comparison sample from individuals who used housing services other than PSH, as use of these services was indicative of episodic or chronic homelessness. If individuals later became stably housed, we would likely underestimate savings attributable to PSH. Third, approximately $28 \%$ of our treatment sample left PSH during the study period. We retained these individuals in the study, but were unable to ascertain their housing status after they left PSH. Fourth, we do not have data on whether or not individuals in our comparison group were eligible for PSH and declined, or were not given the opportunity to receive it, and this may bias our results in an unknown direction. We also do not have data on length of homelessness prior to starting PSH. Finally, our analysis is limited to a subset of 54 of 67 counties in Pennsylvania and excludes Philadelphia, which may limit the generalizability of our findings. However, our study population is substantially larger and more geographically diverse than prior analyses of PSH. ${ }^{4,} 8-10,14,27,36$ Pennsylvania has the fifthlargest Medicaid program in the country, which enhances the potential generalizability of our estimates.

Within our study period, PSH experienced the largest growth of all publicly financed housing programs for homeless people in Pennsylvania, broadening the program's enrollment and underscoring its salience to policymakers. ${ }^{3} \mathrm{We}$ found reductions in spending associated with receiving PSH, and also found that adults, many of whom had pre-existing behavioral health disorders, increasingly received treatment for these conditions in outpatient as opposed to acute care settings after receiving PSH. To our knowledge, this is one of the first studies to examine health care expenditures and use 3 years after the start of PSH. Our findings suggest that states looking to use waivers to provide housing services to Medicaid enrollees may realize long-term savings that partially offset the higher costs of providing these services and shift care away from acute and emergency settings.

Supplementary Information The online version contains supplementary material available at https://doi.org/10.1007/s11606-02006465-y.

Acknowledgments: This study was supported by an intergovernmental agreement between the Pennsylvania Department of Human Services (PA DHS) and the University of Pittsburgh. Dr. Hollander was supported by a National Institute of Mental Health training grant (T32 MH 109436). The authors thank Lingshu Xue for her data analysis support. 
Corresponding Author: Mara A. G. Hollander, PhD; Department of Health Policy and Management, Johns Hopkins Bloomberg School of Public Health, Baltimore, MD, USA (e-mail: mholla23@jhu.edu).

\section{Compliance with ethical standards:}

Conflict of Interest: The authors report no conflicts of interest.

\section{REFERENCES}

1. Azar AM. The Root of the Problem: America's Social Determinants of Health. Speech given at Hatch Foundation for Civility and Solutions: Documented by U.S. Department of Health and Human Services. Accessed at https://www.hhs.gov/about/leadership/secretary/ speeches/2018-speeches/theroot-of-the-problem-americas-social-determinants-of-health.html

2. Wilkins C, Burt M, Locke G. A Primer on Using Medicaid for People Experiencing Chronic Homelessness and Tenants in Permanent Supportive Housing. In: Associates A, ed. U.S. Department of Health and Human Services Assistant Secretary for Planning and Evaluation, Office of Disability, Aging and Long-Term Care Policy; 2014.

3. Khanzhina YP, DeWalt B, Teisher $\mathbf{K}$, Baker WL, Kreiger M. Homelessness in Pennsylvania: Causes, Impacts, and Solutions. Harrisburg, PA: Task Force and Advisory Committee, General Assembly of the Commonwealth of Pennsylvania; 2016.

4. National Academies of Sciences Engineering and Medicine. Permanent Supportive Housing: Evaluating the Evidence for Improving Health Outcomes Among People Experiencing Chronic Homelessness. Washington, DC: The National Academies Press; 2018.

5. Waivers. Accessed at https://www.macpac.gov/medicaid-101/waivers/ on 5 June 2019

6. Lipton FR, Nutt S, Sabatini A. Housing the homeless mentally ill: a longitudinal study of a treatment approach. Hosp Community Psychiatry. 1988;39(1):40-5.

7. Gulcur L, Stefancic A, Shinn M, Tsemberis S, Fischer SN. Housing, hospitalization, and cost outcomes for homeless individuals with psychiatric disabilities participating in continuum of care and housing first programmes. J Community Appl Soc Psychol. 2003;131(2):171-86.

8. Sadowski LS, Kee RA, VanderWeele TJ, Buchanan D. Effect of a housing and case management program on emergency department visits and hospitalizations among chronically ill homeless adults: a randomized trial. JAMA. 2009;301(17):1771-8.

9. Culhane DP, Metraux S, Hadley T. Public Service Reductions Associated with Placement of Homeless Persons with Severe Mental Illness in Supportive Housing. Hous Policy Debate. 2002;13(1):107-63.

10. Martinez TE, Burt MR. Impact of permanent supportive housing on the use of acute care health services by homeless adults. Psychiatr Serv. 2006;57(7):992-9.

11. Gilmer TP, Manning WG, Ettner SL. A cost analysis of San Diego County's REACH program for homeless persons. Psychiatr Serv. 2009;60(4):445-50.

12. Srebnik D, Connor T, Sylla L. A pilot study of the impact of housing firstsupported housing for intensive users of medical hospitalization and sobering services. Am J Public Health. 2013;103(2):316-21.

13. McGinnis S, Polvere L, Smith D, Dewar D. Medicaid Redesign Team Supportive Housing Evaluation: Utilization Report 1. Albany, NY: Center for Human Services Research, University at Albany, State University of New York; 2017

14. Gilmer TP, Stefancic A, Ettner SL, Manning WG, Tsemberis S. Effect of full-service partnerships on homelessness, use and costs of mental health services, and quality of life among adults with serious mental illness. Arch Gen Psychiatry. 2010;67(6):645-52.

15. Lim S, Gao Q, Stazesky E, Singh TP, Harris TG, Levanon Seligson A Impact of a New York City supportive housing program on Medicaid expenditure patterns among people with serious mental illness and chronic homelessness. BMC Health Serv Res. 2018;18(1): 15.

16. Rosenheck R, Kasprow W, Frisman L, Liu-Mares W. Cost-effectiveness of supported housing for homeless persons with mental illness. Arch Gen Psychiatry. 2003;60(9):940-51.
17. Aubry T, Tsemberis S, Adair CE, Veldhuizen S, Streiner D, Latimer E, et al. One-year outcomes of a randomized controlled trial of housing first with ACT in five Canadian cities. Psychiatr Serv. 2015;66(5):463-9.

18. Somers JM, Moniruzzaman A, Palepu A. Changes in daily substance use among people experiencing homelessness and mental illness: 24month outcomes following randomization to Housing First or usual care. Addiction. 2015;110(10): 1605-14.

19. Siegel CE, Samuels J, Tang DI, Berg I, Jones K, Hopper K. Tenant outcomes in supported housing and community residences in New York City. Psychiatr Serv. 2006;57(7):982-91.

20. Tsai J, Mares AS, Rosenheck RA. A multi-site comparison of supported housing for chronically homeless adults: "housing first" versus "residential treatment first”. Psychol Serv. 2010;7(4):219-32.

21. Wolitski RJ, Kidder DP, Pals SL, Royal S, Aidala A, Stall R, et al. Randomized trial of the effects of housing assistance on the health and risk behaviors of homeless and unstably housed people living with HIV. AIDS Behav. 2010;14(3):493-503.

22. Dickey B, Gonzalez O, Latimer E, Powers K, Schutt R, Goldfinger S. Use of mental health services by formerly homeless adults residing in group and independent housing. Psychiatr Serv. 1996;47(2):152-8.

23. PA Homeless Management Information System. Accessed at https:// dced.pa.gov/housing-and-development/individuals-households / homelessmanagement-information-system-hmis/

24. Czajka J, Verghese S. Social Security Numbers in Medicaid Records: Reporting and Validity, 2009 Final Report;2013. Accessed at https:// www.cms.gov/research-statistics-data-and-systems/computer-dataand-systems/medicaiddatasourcesgeninfo/downloads/finalssnreport. pdf

25. Sommers BD, Rosenbaum S. Issues in health reform: how changes in eligibility may move millions back and forth between Medicaid and insurance exchanges. Health Aff (Millwood). 2011;30(2):228-36.

26. Kronick R, Gilmer T, Dreyfus T, Lee L. Improving health-based payment for Medicaid beneficiaries: CDPS. Health Care Financ Rev. 2000;21(3):29-64.

27. Basu A, Kee R, Buchanan D, Sadowski LS. Comparative cost analysis of housing and case management program for chronically ill homeless adults compared to usual care. Health Serv Res. 2012;47(1 Pt 2):523-43.

28. Martin EJ. Affordable housing, homelessness, and mental health: what heath care policy needs to address. J Health Hum Serv Adm. 2015;38(1):67-89.

29. Bowen EA. A multilevel ecological model of HIV risk for people who are homeless or unstably housed and who use drugs in the Urban United States. Soc Work Public Health. 2016;31(4):264-75.

30. Mackelprang JL, Collins SE, Clifasefi SL. Housing First is associated with reduced use of emergency medical services. Prehosp Emerg Care. 2014; 18(4):476-82

31. Mullahy J. Much ado about two: reconsidering retransformation and the two-part model in health econometrics. J Health Econ. 1998;17(3):24781.

32. The U.S. Department of Housing and Urban Development, Office of Community Planning and Development. The 2016 Annual Homeless Assessment Report (AHAR) to Congress Part 2: Estimates of Homelessness in the United States; 2017. Accessed at https://files.hudexchange. info/resources/documents/2016-AHAR-Part-2.pdf

33. Rhoades H, Wenzel SL, Henwood BF. Changes in self-rated physical health after moving into permanent supportive housing. Am J Health Promot. 2019;33(7):1073-6.

34. Treglia D, Johns EL, Schretzman M, Berman J, Culhane DP, Lee DC, et al. When crises converge: hospital visits before and after shelter use among homeless New Yorkers. Health Aff (Millwood). 2019;38(9):1458-67.

35. DiPietro B, Artiga S, Gates A. Early Impacts of the Medicaid Expansion for the Homeless Population. Kaiser Family Foundation; 2014. Accessed at http://files.kff.org/attachment/early-impacts-of-the-medicaid-expansion-for-the-homeless-population-issue-brief

36. Buchanan D, Kee R, Sadowski LS, Garcia D. The health impact of supportive housing for HIV-positive homeless patients: a randomized controlled trial. Am J Public Health. 2009;99 Suppl 3:S675-80.

Publisher's Note: Springer Nature remains neutral with regard to jurisdictional claims in published maps and institutional affiliations. 